\title{
Why do men have worse COVID-19-related outcomes? A systematic review and meta-analysis with sex adjusted for age
}

\author{
J. Fabião ${ }^{1 \oplus}$, B. Sassi ${ }^{1 \oplus}$, E.F. Pedrollo ${ }^{2 \oplus}$, F. Gerchman ${ }^{2 \oplus}$, C.K. Kramer ${ }^{3 \oplus}$, C.B. Leitão ${ }^{2 \oplus}$, and \\ L.C. Pinto ${ }^{1,20 凶}$ \\ ${ }^{1}$ Divisão de Medicina Interna, Hospital Nossa Senhora da Conceição, Porto Alegre, RS, Brasil \\ ${ }^{2}$ Programa de Pós-Graduação em Ciências Médicas: Endocrinologia, Divisão de Endocrinologia, Hospital de Clínicas de \\ Porto Alegre, Universidade Federal do Rio Grande do Sul, Porto Alegre, RS, Brasil \\ ${ }^{3}$ Mount Sinai Hospital, University of Toronto, Toronto, Ontario, Canada
}

\begin{abstract}
We aimed to study the mechanism behind worse coronavirus disease-19 (COVID-19) outcomes in men and whether the differences between sexes regarding mortality as well as disease severity are influenced by sex hormones. To do so, we used age as a covariate in the meta-regression and subgroup analyses. This was a systematic search and meta-analysis of observational cohorts reporting COVID-19 outcomes. The PubMed (Medline) and Cochrane Library databases were searched. The primary outcome was COVID-19-associated mortality and the secondary outcome was COVID-19 severity. The study was registered at PROSPERO: 42020182924. For mortality, men had a relative risk of $1.36\left(95 \% \mathrm{Cl}: 1.17\right.$ to $1.59 ; l^{2} 63 \%, \mathrm{P}$ for heterogeneity $<0.01)$ compared to women. Age was not a significant covariate in meta-analysis heterogeneity $(P=0.393)$ or subgroup analysis. For disease severity, being male was associated with a relative risk of $1.29\left(95 \% \mathrm{Cl}: 1.19\right.$ to $1.40 ; I^{2} 48 \%$, $\mathrm{P}$ for heterogeneity $<0.01)$ compared to the relative risk of women. Again, age did not influence the outcomes of the metaregression $(P=0.914)$ or subgroup analysis. Men had a higher risk of COVID-19 mortality and severity regardless of age, decreasing the odds of hormonal influences in the described outcomes.
\end{abstract}

Key words: COVID-19; Sexual hormone; Meta-analysis

\section{Introduction}

In late 2019, the world was introduced to a new virus that was first described in the city of Wuhan, China. This virus was later named severe acute respiratory syndrome coronavirus 2 (SARS-CoV-2), and the related clinical syndrome was named coronavirus disease 2019 (COVID19). Soon, COVID-19 spread worldwide and reached pandemic proportions in March 2020 (1). It was estimated that by September 2021, more than 219 million people around the globe were infected by COVID-19, with more than 4 million deaths.

Several reports have identified risk factors for disease severity and mortality, especially older age, hypertension, diabetes, obesity, and cardiovascular disease. Nonetheless, the same reports showed an increased risk of complications in men (2). Notably, among the nine deaths initially reported in Italy in patients younger than 40 years, eight were men $(2,3)$. The difference in clinical presentation between men and women may be directly mediated by sex hormones (4). As testosterone physiologically decreases in older males (5), age may play an important role in mediating adverse COVID-19 outcomes according to sex. In this sense, differences in COVID-19 severity and mortality between men and women would be greater in younger patients and the magnitude of the association would be weakened as age increases, following the predicted decrease in testosterone production in older people. With this in mind, we aimed to assess the differences between the sexes regarding mortality as well as severity of COVID-19, taking into account age as a covariate, evaluated by meta-regression and subgroup analyses.

\section{Material and Methods}

We performed a systematic search and meta-analysis of observational cohorts reporting COVID-19 outcomes,

Correspondence: L.C. Pinto: <lanacfp@gmail.com> | <lcfpinto@hcpa.edu.br> 
which included detailed descriptions of patients' clinical profiles and disease severity (according to authors' definition: peripheral oxygen saturation of $<90 \%$, need for intensive care unit admission, and/or need for mechanical ventilation) and/or mortality. The PubMed (Medline) and Cochrane Library databases were searched up to May 13th, 2021. The primary outcome was COVID-19-associated mortality and the secondary outcome was COVID-19 severity. This systematic review and meta-analysis was registered in PROSPERO (registration number 42020182924).

The collected data included the author's name, year of publication, country of publication, and ages of the included participants, as well as the difference in age between groups, number of patients with severe COVID19, number of patients with mild/moderate COVID-19, number of deaths due to COVID-19, and number of survivors. Data were extracted by two researchers (J.F. and B.S.), disagreements were solved by a third party (L.C.P.) and the quality of the analyzed studies was assessed using the Meta-Analyses of Observational Studies in Epidemiology (MOOSE) Guidelines (6).

We performed direct meta-analyses and calculated the relative risk for both outcomes (COVID-19 mortality and severity). To analyze the influence of age on the outcomes (as a surrogate variable for hormonal reserve), we performed meta-regression using the mean age of study participants as a covariate. Furthermore, subgroup meta-analyses according to study participants' mean age (below 50 years, 51-60 years, and above 60 years) were planned. Heterogeneity was assessed by the Cochran $Q$ test (a $P$ value of 0.1 was considered statistically significant) and the $I^{2}$ test (values greater than $50 \%$ were considered to indicate elevated statistical heterogeneity). Publication bias was assessed by funnel plot analysis. Analyses were performed using $R$ software version 4.0.3 "Bunny-Wunnies Freak Out" (The R Foundation for Statistical Computing).

\section{Results}

The initial search retrieved 3321 articles. Six hundred ninety-six articles were published prior to 2019 and were excluded. Of the remaining articles, 16 studies had information about patient sex and COVID-19-associated mortality $(20,601$ patients) and 46 had information on disease severity (12,513 patients) (Figure 1).

Men had a relative risk of mortality of $1.36(95 \% \mathrm{Cl}$ : 1.17 to $1.59 ; I^{2} 63 \%$, P for heterogeneity $<0.01$, Figure 2; 7-22) compared with women. Age did not affect the outcomes in the meta-regression $(P=0.393)$. The subgroup analysis was performed with studies pooled into two groups (cutoff of 60 years) because only one study with a mean participant age below 50 years was identified. Men younger than 60 years had a RR of $1.53(95 \% \mathrm{Cl}: 0.96$ to $2.43 ; I^{2} 18 \%$, P for heterogeneity $0.29 ; 4$ studies), while

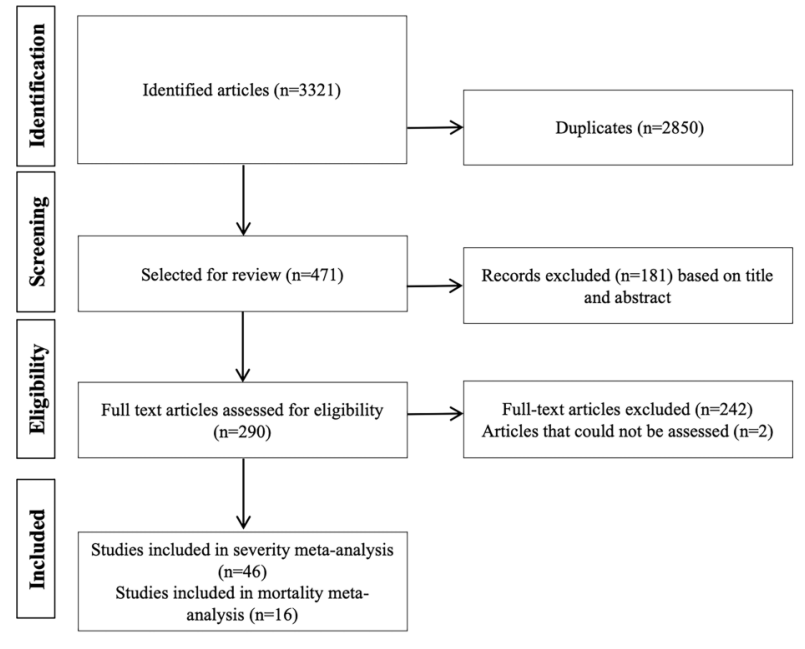

Figure 1. Study flowchart.

those above 60 years of age had a RR of $1.54(95 \% \mathrm{Cl}$ : 1.29 to $1.83 ; I^{2} 0 \%$, P for heterogeneity $0.67 ; 9$ studies). The RR for mortality in men younger than 60 years was not significant. However, the magnitude of the association was similar to that found in older subjects (1.53 vs 1.54), and this particular meta-analysis was based only on four studies $(10,13,19,22)$, which probably lacks power to reach definitive conclusions in this subgroup.

For disease severity, being male was associated with a relative risk of $1.29\left(95 \% \mathrm{Cl}: 1.19\right.$ to $1.40 ; l^{2} 48 \%, \mathrm{P}$ for heterogeneity $<0.01$ ) compared to females (Figure 3; $9,10,12,14,15,19,23-62)$. Age again was not a significant covariate implicated in meta-analysis heterogeneity identified by meta-regression ( $p=0.914)$. The subgroup analysis included studies classified based on patients' mean age in three strata: below 50 years, 51-60 years, and above 60 years. In this analysis, the magnitude of the association of male sex and COVID-19 severity was similar regardless of age group: the group of patients $<50$ years old had an RR of $1.37(95 \% \mathrm{Cl}$ : 1.01 to 1.86 ; $I^{2} 44 \%$, P for heterogeneity 0.06 ; 11 studies), the group of patients aged $51-60$ years had an RR of $1.32(95 \% \mathrm{Cl}$ : 1.11 to $1.56 ; I^{2} 57 \%$, P for heterogeneity $<0.01,18$ studies), and the group of patients aged $>60$ years had a RR of 1.24 (95\% Cl: 1.12 to $1.38 ; I^{2} 37 \%$, P for heterogeneity $0.08,14$ studies). The quality assessment of the included studies is presented in Supplementary Tables S1 (7-22) and S2 $(9,10,12,14,15,19,23-62)$, showing an overall good quality, and no publication bias was identified after inspection of the funnel plot (Supplementary Figure S1).

\section{Discussion}

This systematic review and meta-analysis confirmed that COVID-19 severity and mortality are increased in men. Age was not an important cofactor modulating these 


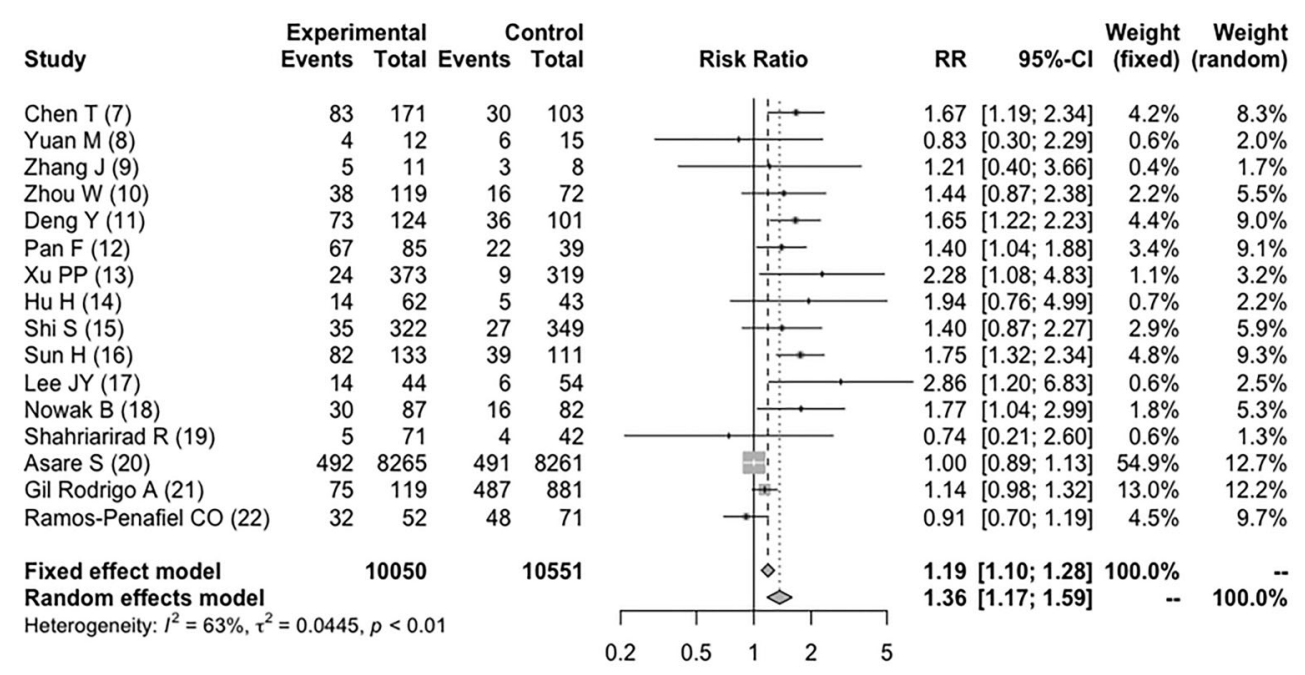

Figure 2. Forest plot for COVID-19 mortality in male patients.

interactions, as associations were maintained at similar levels across all age strata.

The higher rate of mortality in men with COVID-19 may be explained by several factors. There are some differences between male and female detection of nucleic acids by innate immunity, with pattern recognition receptors (PRRs) differing between the sexes (63). The Toll-like receptor 7 (TLR7) gene may escape $X$ inactivation, resulting in higher expression levels of TLR7 in females than in males (64). Moreover, in vitro experiments have shown that the exposure of peripheral blood mononuclear cells (PBMCs) to TLR7 ligands causes higher production of interferon-- $\alpha$ (IFN- $\alpha$ ) in cells in women than in men, and plasmacytoid dendritic cells ( $p D C s$ ) from female humans have higher basal levels of IFN regulatory factor 5 (IRF5) and IFN- $\alpha$ production following TLR7 ligand stimulation (65). A review that examined the association between sex differences in the immune system concluded that sex-based immunological differences contribute to variations in susceptibility to infectious diseases. For example, sex differences in human leukocyte antigen (HLA) alleles and genes that encode for the interleukin (IL) receptors IL-4, IL-10, and IL-12 have each been associated with differential antibody responses to several vaccines in children and adults. In those cases, hormonal mechanisms are hypothesized to be implicated (66). Another review documented that women, especially during the reproductive years, are at increased risk of developing autoimmune diseases but are more resistant to infections than men, which might be mediated by several factors, including sex hormones $(66,67)$. The concept of sex-based immunological differences driven by sex hormones and the $X$ chromosome has been well described by Elgendy et al. (68). Angiotensin-converting enzyme-2 (ACE2) encoded by the ACE 2 gene has been proven to be the receptor for both SARS coronavirus (SARS-CoV) and human respiratory coronavirus NL63 (69). Different studies have quantified the expression of ACE 2 proteins in human cells based on sex and ethnicity. The expression level and pattern of human ACE 2 using single-cell RNA sequencing (RNA-seq) indicates that Asian males have higher expression of ACE 2 than females (70).

Interestingly, the blockage of estrogen receptors increased mortality from SARS-CoV infection in female mice, suggesting a role for estrogen receptors in modulating responses to viral infections. Similarly, theories regarding a benefit of testosterone blockage have been postulated $(70,71)$. Based on this interesting but unproven hypothesis, clinical trials are recruiting volunteers to test the effect of lowering testosterone production or action in men infected by SARS-CoV-2. Clinical trials are testing two anti-androgen medications: degarelix acetate (an LHRH analog that decreases pituitary gonadotrophin release and ultimately testosterone production) (72) and dutasteride (a 5-alpha reductase inhibitor that blocks the enzyme that converts testosterone to a more potent androgen, dihydrotestosterone) (73). Additionally, results from a controversial study analyzing the effect of proxalutamide (an androgen receptor antagonist) have been recently published (74).

However, our meta-analysis results do not support the "hormonal theory". If higher testosterone values were the sole factor responsible for sex differences in COVID-19 outcomes, a decrease in the magnitude of the association would be expected as patient age increased. Additionally, if estrogen were a protective factor, the "sex gap" would decrease with older age, as it seems to for cardiovascular disease incidence among men and women (75). This phenomenon was not observed in our study. In our 


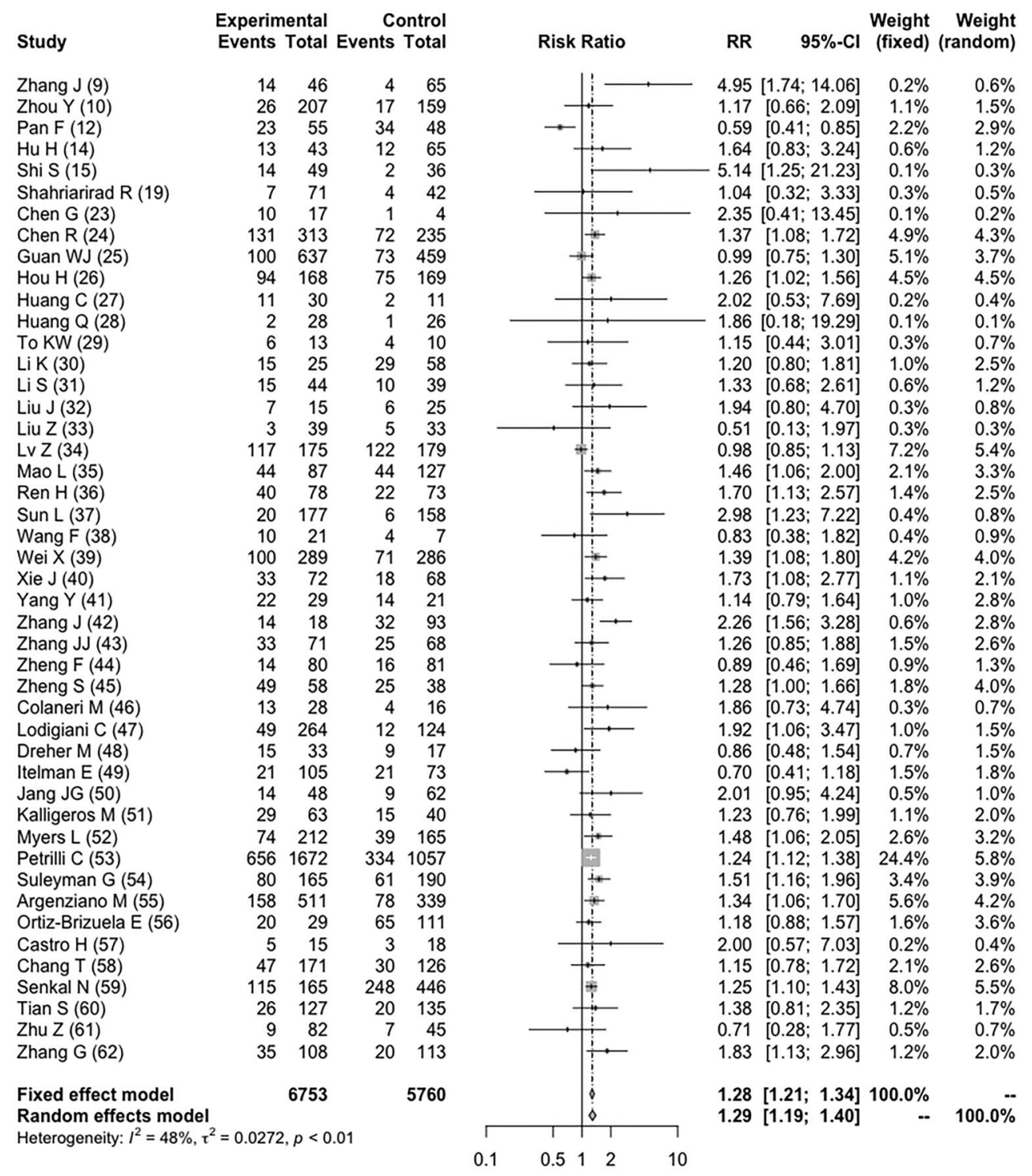

Figure 3. Forest plot for COVID-19 severity in male patients.

analysis, the magnitude of the association between COVID-19 outcomes and male sex was unchanged and not modulated by age.

Our findings may have two explanations. First, the similar RR for disease severity observed in younger (presumably, with higher testosterone production) and older men (with lower testosterone production) may reflect different factors determining outcomes across ages. In young healthy men, testosterone may have implications in disease severity, while in older men, other factors, such as the increased prevalence of obesity, diabetes, hypertension, and cardiovascular disease, surpass the possible protection of lower testosterone production. Second and most likely, other theories, in addition to testosterone effects, would explain the worse outcomes observed in men. Different outcomes for men and women might be due to health behaviors, as men are more prone to smoke and be heavy drinkers than women (76). Additionally, other risk factors for COVID-19 severity, such as hypertension and cardiovascular disease, are more prevalent in men. Furthermore, a study conducted in Spain reported that women had more responsible attitudes toward the COVID-19 pandemic than men (77). Some shortcomings of the current analysis should be highlighted. Given the observational nature of the included studies and the pooled analysis that characterizes a meta-analysis, it was not possible to directly assess the effects of hormonal values or to isolate age from sex at the individual level. 
A direct assessment would only be possible if we had access to individual data to perform meta-analysis on data at the individual level. Additionally, the number of studies reporting mortality was low, precluding sufficient power to properly conduct the meta-regression.

In conclusion, this meta-analysis, unlike others $(78,79)$, assessed the possible interaction among sex, age, and COVID-19 mortality and severity. Men are at higher risk for COVID-19 mortality and severe cases regardless of age, decreasing the odds for hormonal influences in the described outcomes. Further studies, including a meta-analysis with data at the patient level, should be conducted to clarify the mechanisms for poorer outcomes among men with COVID-19.

\section{References}

1. Jotz GP, Stein A, Sirena S, Barros E, Baldisserotto J, de Figueiredo JAP, et al. The COVID-19 pandemic and planetary health. a critical review of epidemiology, prevention, clinical characteristics and treatments for oral, head and neck health professionals. Do we have a roadmap? Int Arch Otorhinolaryngol 2020; 24: e351-e358, doi: 10.1055/s0040-1714143.

2. Xie J, Tong Z, Guan X, Du B, Qu H. Clinical characteristics of patients who died of coronavirus disease 2019 in China. JAMA Netw Open 2020; 3: e205619, doi: 10.1001/ jamanetworkopen.2020.5619.

3. Lippi G, Mattiuzzi C, Sanchis-Gomar F, Henry BM. Clinical and demographic characteristics of patients dying from COVID-19 in Italy vs China. J Med Virol 2020; 92: 17591760, doi: 10.1002/jmv.25860.

4. Giagulli VA, Guastamacchia E, Magrone T, Jirillo E, Lisco G, De Pergola G, et al. Worse progression of COVID-19 in men: is testosterone a key factor? Andrology 2021; 9: 5364, doi: 10.1111/andr.12836.

5. Harman SM, Metter EJ, Tobin JD, Pearson J, Blackman MR, Baltimore Longitudinal Study of Aging. Longitudinal effects of aging on serum total and free testosterone levels in healthy men. Baltimore longitudinal study of aging. J Clin Endocrinol Metab 2001; 86: 724-731, doi: 10.1210/jcem.86.2.7219.

6. Stroup DF, Berlin JA, Morton SC, Olkin I, Williamson GD, Rennie D, et al. Meta-analysis of observational studies in epidemiology: a proposal for reporting. Meta-analysis of observational studies in epidemiology (MOOSE) group. JAMA 2000; 283: 2008-2012, doi: 10.1001/jama.283.15.2008.

7. Chen $T$, Wu D, Chen $H$, Yan W, Yang D, Chen G, et al. Clinical characteristics of 113 deceased patients with coronavirus disease 2019: retrospective study. BMJ 2020; 368: m1295, doi: 10.1136/bmj.m1091.

8. Yuan M, Yin W, Tao Z, Tan W, Hu Y. Association of radiologic findings with mortality of patients infected with 2019 novel coronavirus in Wuhan, China. PLoS One 2020; 15: e0230548, doi: 10.1371/journal.pone.0230548.

9. Zhang J, Liu P, Wang M, Wang J, Chen J, Yuan W, et al. The clinical data from 19 critically ill patients with coronavirus disease 2019: a single-centered, retrospective, observational study. Z Gesundh Wiss 2020; 1-4, doi: 10.1007/ s10389-020-01291-2.

\section{Supplementary Material}

Click here to view [pdf].

\section{Acknowledgments}

C.B. Leitão is a recipient of a $P Q$ scholarship from CNPq. C.K. Kramer received a research grant from Boehringer Ingelheim and is a recipient of the Canadian Diabetes Association Clinician-Scientist award. This work was funded by CAPES, Conselho Nacional de Desenvolvimento Científico e Tecnológico (CNPq), and Fundo de Incentivo à Pesquisa do Hospital de Clínicas de Porto Alegre (FIPE).

10. Zhou W, Liu Y, Tian D, Wang C, Wang S, Cheng J, et al. Potential benefits of precise corticosteroids therapy for severe 2019-nCoV pneumonia. Signal Transduct Target Ther 2020; 5: 18, doi: 10.1038/s41392-020-0127-9.

11. Deng $Y$, Liu W, Liu K, Fang YY, Shang J, Zhou L, et al. Clinical characteristics of fatal and recovered cases of coronavirus disease 2019 in Wuhan, China: a retrospective study. Vol. 133, Chin Med J (Engl) 2020; 133: 1261-1267, doi: 10.1097/CM9.0000000000000824.

12. Pan F, Yang L, Li Y, Liang B, Li L, Ye T, et al. Factors associated with death outcome in patients with severe coronavirus disease-19 (COVID-19): a case-control study. Int J Med Sci 2020; 17: 1281-1292, doi: 10.7150/ijms. 46614.

13. Xu PP, Tian RH, Luo S, Zu ZY, Fan B, Wang XM, et al. Risk factors for adverse clinical outcomes with COVID-19 in China: a multicenter, retrospective, observational study. Theranostics 2020; 10: 6372-6383, doi: 10.7150/thno. 46833.

14. Hu H, Yao N, Qu Y. Comparing rapid scoring systems in mortality prediction of critically ill patients with novel coronavirus disease. Acad Emerg Med 2020; 27: 461468, doi: 10.1111/acem.13992.

15. Shi S, Qin M, Cai $Y$, Liu T, Shen B, Yang F, et al. Characteristics and clinical significance of myocardial injury in patients with severe coronavirus disease 2019. Eur Heart J 2020; 41: 2070-2079, doi: 10.1093/eurheartj/ ehaa408.

16. Sun H, Ning R, Tao Y, Yu C, Deng X, Zhao C, et al. Risk factors for mortality in 244 older adults with COVID-19 in Wuhan, China: a retrospective study. J Am Geriatr Soc 2020; 68: E19-E23, doi: 10.1111/jgs.16533.

17. Lee JY, Kim HA, Huh K, Hyun M, Rhee JY, Jang S, et al. Risk factors for mortality and respiratory support in elderly patients hospitalized with COVID-19 in Korea. J Korean Med Sci 2020; 35: e223, doi: 10.3346/jkms.2020.35.e223.

18. Nowak B, Szymański P, Pańkowski I, Szarowska A, Życińska K, Rogowski W, et al. Clinical characteristics and short-term outcomes of patients with coronavirus disease 2019: a retrospective single-center experience of a designated hospital in Poland. Pol Arch Intern Med 2020; 130: 407-411, doi: 10.20452/pamw.15361 . 
19. Shahriarirad R, Khodamoradi Z, Erfani A, Hosseinpour $H$, Ranjbar K, Emami Y, et al. Epidemiological and clinical features of 2019 novel coronavirus diseases (COVID-19) in the South of Iran. BMC Infect Dis 2020; 20: 427, doi: 10.1186/s12879-020-05128-x.

20. Asare S, Sandio A, Opara IN, Riddle-Jones L, Palla M, Renny $\mathrm{N}$, et al. Higher obesity trends among African Americans are associated with increased mortality in infected COVID-19 patients within the city of Detroit. SN Compr Clin Med 2020; 1-3.

21. Gil-Rodrigo A, Miró Ò, Piñera $P$, Burillo-Putze $G$, Jiménez $S$, Martín $A$, et al. Analysis of clinical characteristics and outcomes in patients with COVID-19 based on a series of 1000 patients treated in Spanish emergency departments. Emergencias 2020; 32: 233-241.

22. Ramos-Peñafiel CO, Santos-González B, Flores-López EN, Galván-Flores F, Hernández-Vázquez L, Santoyo-Sánchez A, et al. Utilidad de los índices neutrófilo/linfocito, monocito/ linfocito y linfocito/plaqueta para el pronóstico de complicaciones asociadas a COVID-19 [in Spanish]. Gaceta Med Mexico 2020; 156: 413-419, doi: 10.24875/gmm.20000458.

23. Chen G, Wu D, Guo W, Cao Y, Huang D, Wang H, et al. Clinical and immunological features of severe and moderate coronavirus disease 2019. J Clin Invest 2020; 130: 26202629, doi: 10.1172/JCl137244.

24. Chen R, Sang L, Jiang M, Yang Z, Jia N, Fu W, et al. Longitudinal hematologic and immunologic variations associated with the progression of COVID-19 patients in China. $J$ Allergy Clin Immunol 2020; 146: 89-100, doi: 10.1016/j. jaci.2020.05.003.

25. Guan WJ, Ni ZY, Hu Y, Liang WH, Ou CQ, He JX, et al. Clinical characteristics of coronavirus disease 2019 in China. N Engl J Med 2020; 382: 1708-1720, doi: 10.1056/ NEJMoa2002032.

26. Hou H, Zhang B, Huang H, Luo Y, Wu S, Tang G, et al. Using IL-2R/lymphocytes for predicting the clinical progression of patients with COVID-19. Clin Exp Immunol 2020; 201: 7684, doi: 10.1111/cei.13450.

27. Huang C, Wang Y, Li X, Ren L, Zhao J, Hu Y, et al. Clinical features of patients infected with 2019 novel coronavirus in Wuhan, China. Lancet 2020; 395: 497-506, doi: 10.1016/ S0140-6736(20)30183-5.

28. Huang Q, Deng X, Li Y, Sun X, Chen Q, Xie M, et al. Clinical characteristics and drug therapies in patients with the common-type coronavirus disease 2019 in Hunan, China. Int J Clin Pharm 2020; 42: 837-845, doi: 10.1007/s11096020-01031-2.

29. To KKW, Tsang OTY, Leung WS, Tam AR, Wu TC, Lung DC, et al. Temporal profiles of viral load in posterior oropharyngeal saliva samples and serum antibody responses during infection by SARS-CoV-2: an observational cohort study. Lancet Infect Dis 2020; 20: 565-574, doi: 10.1016/ S1473-3099(20)30196-1.

30. Li K, Wu J, Wu F, Guo D, Chen L, Fang Z, et al. The clinical and chest CT features associated with severe and critical COVID-19 pneumonia. Invest Radiol 2020; 55: 327-331, doi: 10.1097/RLI.0000000000000672.

31. Li S, Jiang L, Li X, Lin F, Wang Y, Li B, et al. Clinical and pathological investigation of patients with severe COVID-19. $\mathrm{JCl}$ Insight 2020; 5: e138070, doi: 10.1172/jci.insight. 138070 .
32. Liu J, Li S, Liu J, Liang B, Wang X, Wang H, et al. Longitudinal characteristics of lymphocyte responses and cytokine profiles in the peripheral blood of SARS-CoV-2 infected patients. E Bio Medicine 2020; 55: 102763, doi: 10.1016/j.ebiom.2020.102763.

33. Liu Z, Jin $\mathrm{C}$, Wu CC, Liang $\mathrm{T}$, Zhao $\mathrm{H}$, Wang $\mathrm{Y}$, et al. Association between initial chest CT or clinical features and clinical course in patients with coronavirus disease 2019 pneumonia. Korean J Radiol 2020; 21: 736-745, doi: 10.3348/kjr.2020.0171.

34. Lv Z, Cheng S, Le J, Huang J, Feng L, Zhang B, et al. Clinical characteristics and co-infections of 354 hospitalized patients with COVID-19 in Wuhan, China: a retrospective cohort study. Microbes Infect 2020; 22: 195-199, doi: 10.1016/j.micinf.2020.05.007.

35. Mao L, Jin H, Wang M, Hu Y, Chen S, He Q, et al. Neurologic manifestations of hospitalized patients with coronavirus disease 2019 in Wuhan, China. JAMA Neurol 2020; 77: 683-690, doi: 10.1001/jamaneurol.2020.1127.

36. Ren $H$, Yang $Y$, Wang $F$, Yan $Y$, Shi $X$, Dong $K$, et al. Association of the insulin resistance marker TyG index with the severity and mortality of COVID-19. Cardiovasc Diabetol 2020; 19: 58, doi: 10.1186/s12933-020-01035-2.

37. Sun L, Song F, Shi N, Liu F, Li S, Li P, et al. Combination of four clinical indicators predicts the severe/critical symptom of patients infected COVID-19. J Clin Virol 2020; 128: 104431, doi: 10.1016/j.jcv.2020.104431.

38. Wang F, Yang Y, Dong K, Yan Y, Zhang S, Ren H, et al. Clinical characteristics of 28 patients with diabetes and COVID-19 in Wuhan, China. Endocr Pract 2020; 26: 668674, doi: 10.4158/EP-2020-0108.

39. Wei X, Zeng W, Su J, Wan H, Yu X, Cao X, et al. Hypolipidemia is associated with the severity of COVID-19. J Clin Lipidol 2020; 14: 297-304, doi: 10.1016/j.jacl. 2020.04.008

40. Xie J, Ding C, Li J, Wang Y, Guo H, Lu Z, et al. Characteristics of patients with coronavirus disease (COVID-19) confirmed using an IgM-IgG antibody test. J Med Virol 2020; 92: 2004-2010, doi: 10.1002/jmv.25930.

41. Yang Y, Shen C, Li J, Yuan J, Wei J, Huang F, et al. Plasma IP-10 and MCP-3 levels are highly associated with disease severity and predict the progression of COVID-19. J Allergy Clin Immunol 2020; 146: 119-27.e4, doi: 10.1016/j.jaci. 2020.04.027.

42. Zhang J, Yu M, Tong S, Liu LY, Tang LV. Predictive factors for disease progression in hospitalized patients with coronavirus disease 2019 in Wuhan, China. J Clin Virol 2020; 127: 104392, doi: 10.1016/j.jcv.2020.104392.

43. Zhang JJ, Dong $X$, Cao YY, Yuan YD, Yang YB, Yan YQ, et al. Clinical characteristics of 140 patients infected with SARS-CoV-2 in Wuhan, China. Allergy 2020; 75: 17301741, doi: 10.1111/all.14238.

44. Zheng F, Tang W, Li H, Huang YX, Xie YL, Zhou ZG. Clinical characteristics of 161 cases of corona virus disease 2019 (COVID-19) in Changsha. Eur Rev Med Pharmacol Sci 2020; 24: 3404-3410.

45. Zheng S, Fan J, Yu F, Feng B, Lou B, Zou Q, et al. Viral load dynamics and disease severity in patients infected with SARS-CoV-2 in Zhejiang province, China, January-March 2020: retrospective cohort study. BMJ 2020; 369: m1443, doi: $10.1136 / \mathrm{bmj} \cdot \mathrm{m} 1443$. 
46. Colaneri M, Sacchi P, Zuccaro V, Biscarini S, Sachs M, Roda S, et al. Clinical characteristics of coronavirus disease (COVID-19) early findings from a teaching hospital in Pavia, North Italy, 21 to 28 February 2020. Euro Surveill 2020; 25: 2000460, doi: 10.2807/1560-7917.ES.2020.25.16.2000460.

47. Lodigiani C, lapichino G, Carenzo L, Cecconi M, Ferrazzi P, Sebastian T, et al. Venous and arterial thromboembolic complications in COVID-19 patients admitted to an academic hospital in Milan, Italy. Thromb Res 2020; 191: 9-14, doi: 10.1016/j.thromres.2020.04.024.

48. Dreher M, Kersten A, Bickenbach J, Balfanz P, Hartmann B, Cornelissen $C$, et al. The characteristics of 50 hospitalized COVID-19 patients with and without ARDS. Dtsch Aerztebl Int 2020; 117: 271-278, doi: 10.3238/arztebl.2020.0271.

49. Itelman E, Wasserstrum Y, Segev A, Avaky C, Negru L, Cohen D, et al. Clinical characterization of 162 COVID-19 patients in Israel: preliminary report from a large tertiary center. Isr Med Assoc J 2020; 22: 271-274.

50. Jang JG, Hur J, Choi EY, Hong KS, Lee W, Ahn JH. Prognostic factors for severe coronavirus disease 2019 in Daegu, Korea. J Korean Med Sci 2020; 35: e209, doi: 10.3346/jkms.2020.35.e209.

51. Kalligeros M, Shehadeh F, Mylona EK, Benitez G, Beckwith CG, Chan PA, et al. Association of obesity with disease severity among patients with coronavirus disease 2019. Obesity (Silver Spring) 2020; 28: 1200-1204, doi: 10.1002/ oby.22859.

52. Myers LC, Parodi SM, Escobar GJ, Liu VX. Characteristics of hospitalized adults with COVID-19 in an integrated health care system in California. JAMA 2020; 323: 2195-2198, doi: 10.1001/jama.2020.7202.

53. Petrilli CM, Jones SA, Yang J, Rajagopalan H, O'Donnell L, Chernyak $\mathrm{Y}$, et al. Factors associated with hospital admission and critical illness among 5279 people with coronavirus disease 2019 in New York City: prospective cohort study. BMJ 2020; 369: m1966, doi: 10.1136/bmj.m1966.

54. Suleyman G, Fadel RA, Malette KM, Hammond C, Abdulla $H$, Entz $A$, et al. Clinical characteristics and morbidity associated with coronavirus disease 2019 in a series of patients in Metropolitan Detroit. JAMA Network Open 2020; 3: e2012270, doi: 10.1001/jamanetworkopen.2020.12270.

55. Argenziano MG, Bruce SL, Slater CL, Tiao JR, Baldwin MR, Barr RG, et al. Characterization and clinical course of 1000 patients with coronavirus disease 2019 in New York: retrospective case series. BMJ 2020; 369: m1996, doi: 10.1136/bmj.m1996.

56. Ortiz-Brizuela E, Villanueva-Reza M, González-Lara MF, Tamez-Torres KM, Román-Montes CM, Díaz-Mejía BA, et al. Clinical and epidemiological characteristics of patients diagnosed with COVID-19 in a tertiary care center in Mexico City: a prospective cohort study. Rev Invest Clin 2020; 72 : 165-177, doi: 10.24875/ric.20000211.

57. Castro HM, Canale HL, Ferreyro BL, Prieto MA, Massimino BE, Funtowicz G, et al. Clinical characteristics of coronavirus disease 2019 in a single center of Argentina. Retrospective cohort [in Spanish]. Medicina (B Aires) 2020; 80: 35-43.

58. Chang TS, Ding Y, Freund MK, Johnson R, Schwarz T, Yabu $\mathrm{JM}$, et al. Prior diagnoses and medications as risk factors for COVID-19 in a Los Angeles health system. medRxiv 2020; 2020.07.03.20145581, doi: 10.1101/2020.07.03.20145581.
59. Şenkal N, Meral R, Medetalibeyoğlu A, Konyaoğlu H, Kose $\mathrm{M}$, Tukek T. Association between chronic ACE inhibitor exposure and decreased odds of severe disease in patients with COVID-19. Anatol J Cardiol 2020; 24: 21-29, doi: 10.14744/AnatolJCardiol.2020.57431.

60. Tian S, Hu N, Lou J, Chen K, Kang X, Xiang Z, et al. Characteristics of COVID-19 infection in Beijing. $J$ Infect 2020; 80: 401-406, doi: 10.1016/j.jinf.2020.02.018.

61. Zhu Z, Cai T, Fan L, Lou K, Hua X, Huang Z, et al. Clinical value of immune-inflammatory parameters to assess the severity of coronavirus disease 2019. Int J Infect Dis 2020; 95: 332-339, doi: 10.1016/j.ijid.2020.04.041.

62. Zhang G, Hu C, Luo L, Fang F, Chen Y, Li J, et al. Clinical features and short-term outcomes of 221 patients with COVID-19 in Wuhan, China. J Clin Virol 2020; 127: 104364, doi: 10.1016/j.jcv.2020.104364.

63. Pisitkun P, Deane JA, Difilippantonio MJ, Tarasenko T, Satterthwaite AB, Bolland S. Autoreactive B cell responses to RNA-related antigens due to TLR7 gene duplication. Science 2006; 312: 1669-1672, doi: 10.1126/science. 1124978.

64. Berghöfer B, Frommer T, Haley G, Fink L, Bein G, Hackstein $\mathrm{H}$. TLR7 ligands induce higher IFN- $\alpha$ production in females. J Immunol 2006; 177: 2088-2096, doi: 10.4049/jimmunol. 177.4.2088.

65. Griesbeck M, Ziegler S, Laffont S, Smith N, Chauveau L, Tomezsko $\mathrm{P}$, et al. Sex differences in plasmacytoid dendritic cell levels of IRF5 drive higher IFN- $\alpha$ production in women. $J$ Immunol 2015; 195: 5327-5336, doi: 10.4049/jimmunol. 1501684

66. Klein SL, Flanagan KL. Sex differences in immune responses. Nat Rev Immunol 2016; 16: 626-638, doi: 10.1038/nri.2016.90.

67. Ghazeeri G, Abdullah L, Abbas O. Immunological differences in women compared with men: overview and contributing factors. Am J Reprod Immunol 2011; 66: 163169, doi: 10.1111/j.1600-0897.2011.01052.x.

68. Elgendy IY, Pepine CJ. Why are women better protected from COVID-19: Clues for men? Sex and COVID-19. Int $J$ Cardiol 2020; 315: 105-106, doi: 10.1016/j.ijcard.2020. 05.026.

69. Cao Y, Li L, Feng Z, Wan S, Huang P, Sun X, et al. Comparative genetic analysis of the novel coronavirus (2019-nCoV/SARS-CoV-2) receptor ACE2 in different populations. Cell Discov 2020; 6: 11, doi: 10.1038/s41421-0200147-1.

70. Zhao Y, Zhao Z, Wang Y, Zhou Y, Ma Y, Zuo W. Single-cell rna expression profiling of ACE2, the receptor of SARSCoV-2. Am J Respir Crit Care Med 2020; 202: 756-759, doi: 10.1164/rccm.202001-0179LE.

71. Wang X, Dhindsa R, Povysil G, Zoghbi A, Motelow J, Hostyk $\mathrm{J}$, et al. TMPRSS2 transcriptional inhibition as a therapeutic strategy for COVID-19. 2020, doi: 10.20944/preprints202003.0360.v2.

72. ClinicalTrials.gov. Hormonal Intervention for the Treatment in Veterans With COVID-19 requiring hospitalization (HITCH). ID: NCT04397718. Accessed November 19, 2020.

73. ClinicalTrials.gov. Anti-Androgen treatment for COVID-19. ID: NCT04446429. Accessed November 19, 2020.

74. Schneider L. Why not chemical castration (to escape COVID-19)? Available at: https://forbetterscience.com/ 
2021/03/16/why-not-chemical-castration-to-escape-covid19/. Accessed on June 17, 2021.

75. Vitale C, Mendelsohn ME, Rosano GMC. Gender differences in the cardiovascular effect of sex hormones. Nat Rev Cardiol 2009; 6: 532-542, doi: 10.1038/nrcardio.2009.105.

76. Shim E, Tariq A, Choi W, Lee Y, Chowell G. Transmission potential and severity of COVID-19 in South Korea. Int $J$ Infect Dis 2020; 93: 339-344, doi: 10.1016/j.jijd.2020. 03.031 .

77. de la Vega R, Ruíz-Barquin R, Boros S, Szabo A. Could attitudes toward COVID-19 in Spain render men more vulnerable than women? Glob Public Health 2020; 15: 1278-1291, doi: 10.1080/17441692.2020.1791212.

78. Ortolan A, Lorenzin M, Felicetti M, Doria A, Ramonda R. Does gender influence clinical expression and disease outcomes in COVID-19? A systematic review and metaanalysis. Int J Infect Dis 2020; 99: 496-504, doi: 10.1016/ j.ijid.2020.07.076.

79. Abate BB, Kassie AM, Kassaw MW, Aragie TG, Masresha SA. Sex difference in coronavirus disease (COVID-19): a systematic review and meta-analysis. BMJ Open 2020; 10: e040129, doi: 10.1136/bmjopen-2020-040129. 